\title{
La autoficción: simulacro de teoría o desfiguraciones de un género*
}

Fecha de recepción: 17 de abril de 2017

Fecha de aprobación: 07 de junio de 2017

\section{Resumen}

El objetivo de esta contribución es ofrecer una visión crítica y un balance del estado actual de la reflexión sobre la autoficción en el ámbito hispanoamericano. Con este propósito ubico y analizo los principales lugares comunes en las actuales propuestas teóricas y críticas sobre la autoficción, tratando de demostrar en qué sentidos distorsionan el panorama actual de una teoría de la autoficción todavía en proceso de construcción. Señalar los lugares comunes de la crítica pasa a menudo por el análisis de las lecturas erróneas, que desenfocan planteamientos fundamentales acerca de la naturaleza de la autoficción, así como por la operación de rescate de sentidos esenciales, caídos en el olvido o mistificados. Finalmente, indico algunos caminos a seguir para la crítica, direcciones inexploradas o abandonadas antes de tiempo, que considero valiosas para una teoría de la autoficción. Recuperar la perspectiva sociocultural, que permite emprender la búsqueda del significado del género, ofrece, además, la ventaja de hacer posible un análisis de las particularidades de la autoficción en América Latina - tarea urgente y crucial de la teoría y la crítica literarias contemporáneas -

Palabras clave: autoficción, narrativa hispanoamericana contemporánea, teoría y crítica literarias, debates actuales.

\section{Diana Diaconu}

Profesora e investigadora del Departamento de Literatura de la Universidad Nacional de Colombia, sede Bogotá. Su último libro es: Fernando Vallejo y la autoficción. Coordenadas de un nuevo género narrativo (2013).

dndiaconu@unal.edu.co

*Este artículo de reflexión hace parte de una investigación más amplia, desarrollada gracias a la Beca de Excelencia 2016 del Gobierno de México, otorgada a través de la Secretaría de Relaciones Exteriores. El texto integral se publicará en un libro de próxima aparición.

Citar: Diaconu, D. (enero-junio de 2017). La autoficción: simulacro de teoría o desfiguraciones de un género. La Palabra, (30), 35 - 52. doi: https://doi. org/10.19053/01218530.n30.2017.6964 


\section{Autofiction: Mock Theory or Disfigurement of a Genre}

\section{Abstract}

The aim of this contribution is to provide a critical overview of the current state of reflection on autofiction in Hispanic America. With this purpose I locate and analyze the main clichés in theoretical and critical proposals about autofiction today, attempting to demonstrate the ways in which they distort the current landscape of autofictional theory, still under construction. The task of censoring the clichés of criticism implies analyzing erroneous readings which tend to blur fundamental statements about the nature of autofiction, while rescuing the essential meanings that have been neglected or mystified. Finally, I point out some future challenges for criticism, based on unexplored or prematurely abandoned directions which I consider to be valuable for a theory of autofiction. To recover the sociocultural perspective, which inquires into the meaning of the genre, will also make it possible to analyze the particularities of the genre in Latin America; an urgent and crucial task for contemporary theory andliterarycriticism.

Keywords: autofiction; Hispanic American contemporary narrative; literary theory and criticism, current debate.

\section{L'autofiction: simulacre de théorie ou défiguration d'un genre.}

\section{Résumé}

L'objectif de cette contribution est d'offrir une vision critique et un bilan de l'état actuel de la réflexion sur 1'autofiction dans le domaine hispano-américain. Ainsi, on situe et analyse les lieux communs des principales théories et critiques sur l'autofiction, tout en nous demandant dans quelle mesure celles-ci déformeraient le panorama actuel d'une théorie de l'autofiction toujours en processus de construction. Signaler les lieux communs de la critique passe d'abord par l'analyse de lectures erronées qui s'éloignent des approches fondamentales sur la nature de l'autofiction, ensuite par l'opération qui permet de récupérer les sens essentiels, souvent oubliés ou mystifiés. Finalement, on indique des possibles chemins pour la critique, des directions inexplorées ou abandonnées qu'on considère fort importantes pour une théorie de l'autofiction. La réflexion est déterminé par un champ littéraire (Bourdieu) spécifique. Nous mettons en rapport les possibilités du genre et la prise de position (Bourdieu) représentée par l'oeuvre et un dialogue avec d'autres postures existantes. Cette perspective socio-culturelle permet de réaliser une analyse des particularités du genre d'autofiction en Amérique Latine- devoir urgent et nécessaire de la théorie et la critique littéraire contemporaine.

Palabras clave: autoficción, narrativa hispanoamericana contemporánea, teoría y crítica literarias, debates actuales. 
Para Iván Padilla, primer lector de estas páginas, un cálido agradecimiento.

Introito (con invocación de la musa)

Sin duda, vivimos el momento de la autoficción. Atrás quedan congresos y simposios, mesas redondas, recopilaciones y antologías, antologías de antologías dedicadas, todas, a la minificción: glorias pasadas. Hoy en día, la atención de buena parte de la crítica está puesta en el monstruo bicéfalo rodeado de misterio. Su poderío se extiende como un tumor que amenaza con devorar ávidamente toda la literatura contemporánea; es más, en un incontrolable impulso transgenérico, amenaza nada más y nada menos que al arte contemporáneo. El nombre mágico de la nueva y disforme deidad, autoficción, resuena en todas partes. El oráculo vaticina que pronto, ni en el rincón más remoto del planeta se podrá escribir tesis, libro, artículo crítico o reseña sobre la literatura contemporánea, sin rendirle tributo.

Varias décadas hace que sobre el asunto corren ríos de tinta y saliva y, sin embargo, permanecemos como bajo un mal embrujo: mientras más se escribe, menos claro queda qué se entiende por autoficción. ¿Cuáles son sus señas de identidad? Como en una especie de nebulosa, una tras otra se van esfumando las pocas certezas que hubo en un comienzo sobre el género.
De malentendido en malentendido: problemas de recepción

Los numerosos eventos y publicaciones sobre la autoficción pueden crear la engañosa sensación de que el género se encuentra en el foco de reflexión de importantes teóricos del mundo entero y que, por tanto, la reflexión teórica sobre el género se está desarrollando cada vez más. Los congresos se suceden vertiginosamente citando a especialistas de todo el mundo (¿de todo el mundo?, digamos que de todo el mundo occidental): en septiembre de 2002, en la Universidad de Saint-Étienne; en mayo de 2008, en la Universidad de Lausana; en febrero de 2009, en la Universidad de Bremen; en junio de 2012, en la Universidad de Borgoña; en octubre de 2013, en la Universidad de Alcalá. Desde hace dos años, también los organizan universidades latinoamericanas: en octubre de 2013, la Pontificia Universidad Católica del Perú; y en junio del 2014, la Universidad de Rosario. Se les añaden numerosas mesas redondas y mesas de trabajo de muchos otros congresos con temáticas cada vez más abarcadoras. Tal es el vértigo que produce tanto evento, que algunos críticos empiezan a ver el mundo al revés y dejan entender en sus textos que el auge de la autoficción es consecuencia directa de todos estos congresos celebrados últimamente. En el mundo entero, diligentes y beatos arqueólogos del género descubren yacimientos y reliquias -autoficcionales por doquier. ¿Cervantes?, ¿las monjas?, ¿Berceo o los primeros balbuceos autoficcionales?, ¿los griegos? Los orígenes de la autoficción desaparecen tragados por la noche de lostiempos.

Sin embargo, una vez se logra sortear las distorsiones de la perspectiva debidas a la euforia del momento de efervescencia que estamos viviendo, el panorama actual que se puede vislumbrar obliga a abandonar la visión optimista. Las pocas propuestas sólidas existentes quedan desenfocadas por una recepción viciada, a menudo, por la descontextualización. El afán de ampliar la validez de unas propuestas nacidas en unas circunstancias concretas, convirtiéndolas en verdades universales, hace que dichas propuestas pierdan nitidez, queden desdibujadas. Muchas de las primeras postulaciones del género eran seguramente parciales e incompletas, muy necesitadas de matizaciones, pero certeras dentro de su contexto; ahora se ven convertidas en falsedades de alcance universal. Siguiendo a Lejeune (1994), en cuanto a la importancia otorgada al pacto de lectura, Lecarme enuncia en una verdad de reducido alcance, pero firme: - La autoficción 
es, en el fondo, un dispositivo muy sencillo: un relato cuyo autor, narrador y protagonista comparten la misma identidad nominal y cuya clasificación genérica indica que se trata de una novelall (p. 227). ${ }^{1}$

Sin embargo, al poco tiempo, esta sencilla verdad, que era un buen punto de partida, cae en el olvido y críticos de todo el mundo empiezan a designar como autoficciones obras que proponen pactos narrativos distintos, que generan horizontes de expectativas igualmente diversos. Pozuelo Yvancos (en Casas, 2012) ${ }^{2}$ lo advierte y hace unas correcciones de fondo a la crítica española, muy dada últimamente a convertirlo todo en autoficción. Pero en la misma recopilación donde se reproduce el artículo de Pozuelo Yvancos, y sin ninguna aclaración, se incluye un capítulo que contradice la visión del profesor de la Universidad de Murcia. ${ }^{3}$ En vez de abrir un espacio propicio para el debate, entre todos y desde múltiples puntos de vista, la teorización de la autoficción se ha convertido en un diálogo de sordos.
No se trata de defender aquí, de manera dogmática, un punto de vista, sino de observar críticamente las contradicciones en que incurren las propuestas teóricas que amplían las fronteras de la autoficción según sus conveniencias, sin criterios sólidos, ni hipótesis interpretativa coherente. A menudo, lo hacen invocando la flexibilidad (versus la —rigidez teóricall) como valor en sí, sin reconocer que también la flexibilidad adquiere valor solamente dentro de un contexto cultural determinado: su valor no es intrínseco. Para evitar este tipo de desenfoques, al hacer sin embargo un uso flexible de los conceptos teóricos, concebiré aquí el género literario en el espíritu de Bajtín: como un organismo vivo, nacido no solamente en el contexto estrecho de la historia literaria, sino, sobre todo, en el más amplio, cultural y social, como respuesta a una necesidad histórica. Por tanto, ningún rasgo de índole temática o formal puede ser eterno en un género pensado en su devenir constante, como sucesión sin fin de reformulaciones. En el caso del género autoficcional, la necesidad expresiva mayor a la que responde, y que marca toda nuestra época, es el rechazo del género de la novela, como modelo narrativo caduco: de manera obvia, esto trae consigo la exploración de nuevos caminos para expresar al sujeto contemporáneo, con los retos y problemas que le imponen la crisis del mundo moderno y del posmoderno.

De ahí la aparición de replanteamientos que matizan los supuestos iniciales del género, sin traicionar el sentido de su pacto específico. Puede ocurrir, por ejemplo, que la identidad nominal entre autor, narrador y protagonista no sea un requisito sine qua non y absoluto de la autoficción sino en la medida en que dicha identidad es expresión y consecuencia natural del pacto de lectura propio del género. Así se explica que la crítica más reciente lea Los detectives salvajes de Roberto Bolaño como una autoficción, a pesar de que, al menos en términos estrictamente formales, no hay identidad nominal entre autor, narrador y personaje. Sin embargo, cabe plantear la rebeldía de Bolaño ante el género de la novela y la consiguiente propuesta de un pacto de lectura novedoso, que cuestiona las convenciones

\footnotetext{
${ }^{1}$ La traducción es mía.

${ }^{2}$ El artículo fue publicado originalmente en 2010, en su libro Figuraciones del yo en la narrativa. Javier Marías y E. Vila-Matas.

${ }^{3}$ Se trata del capítulo "Perspectivas hispánicas" del libro La autoficción. Reflexiones teóricas (Casas, 2012). Los tres artículos que lo componen ya habían sido publicados, se concibieron con otros propósitos y resultaron incorporados abusivamente a esta antología. Los primeros dos autores ni siquiera pretenden abordar la autoficción, mientras que el tercero parece "adaptar" rápidamente el texto al tema de la antología. En los tres, el interés que puedan tener sus reflexiones es ajeno o tangencial a la problemática que la antología pretende enfocar, por tanto, no pueden aportar realmente a la reflexión sobre la autoficción.
} 
novelescas y la tradicional concepción del autor ${ }^{4}$.

A menudo se relaciona dicha rebeldía de Roberto Bolaño con su vocación revolucionaria, aunque creo que se precisaría subrayar que entendida como una posición romántica revisitada, una posición más ética que política. Se trata de una actitud vital, de la que surge el constante desafío del discurso hegemónico, y también de la literatura oficial, es decir, de una respuesta necesaria, literaria y vital a la vez, y no de una mera experimentación estética. Así, se establece un pacto autoficcional sin que se dé la identidad nominal entre autor, narrador y personaje, porque lo que se cuestiona es precisamente una concepción de las figuras del autor y del narrador que Roberto Bolaño considera anticuada, caduca. Dinamitando al sujeto concebido como fuente de la verdad y del texto, Roberto Bolaño se propone transgredirlo ${ }^{5}$. Para Angélica Tornero, por poner un ejemplo, Los detectives salvajes de Roberto Bolaño - es una autoficción, que no se define conceptualmente, sino que se expresa como acto performativo que Bolaño llevó a cabo para constituirse; es decir, su escritura es constituyente de sujetos y no está constituida por un sujeto\| (2014, p. 54). La propia forma de la obra, que engendra la figura de un escritor - difícil de descifrar, extraño para él mismoll (2014, p. 54), produce también, a través de sus múltiples y fugaces narradores, otro efecto de sentido cuya importancia en la obra es crucial: la —identidad cambiantell (2014,p.

52) del sujeto contemporáneo.

Este ejemplo demuestra que un género en devenir, sin una preceptiva rígida, pese a que plantea todo tipo de problemas genéricos, no autoriza a incluir en un mismo saco todas las manifestaciones literarias del yo o en primera persona. Desde luego, a la plasticidad del género se suma el autismo del medio académico que tiende a favorecer la recepción errónea de los textos pioneros fundamentales. Hace ya más de dos décadas que, el mismo Pozuelo Yvancos, en Poética de la ficción (1993), había aclarado un malentendido recurrente en la recepción de la propuesta fundamental de Lejeune, tergiversación cuya grave consecuencia es la confusión del pacto autobiográfico con el pacto referencial. En los orígenes de este equívoco, se hallan muchas de las lecturas de la crítica deconstruccionista que, con su fijación en lo textual, se convierte a menudo en un neoformalismo más. Por ejemplo, cuando reduce, como Paul de Man (1991), la propuesta de Lejeune a una vuelta al enfoque contenidista (lo cual la haría dependiente de la contrastación con la realidad extraliteraria), arremetiendo contra lo que le parece ser una concepción extraliteraria y apriorística, en relación con el texto, de la identidad del sujeto.

Sin embargo, en realidad Lejeune (1994) advierte con mucha lucidez las limitaciones de las definiciones tanto contenidistas como formales del género, y su propuesta de definición, según el pacto de lectura, integra estos criterios, pero también los supera. Perfectamente consciente de que la - prueba de verificación\| con -la realidadl, en virtud de la cual se podría concluir la referencialidad de un escrito autobiográfico, no pasa de ser una utopía en el caso de la realidad interior que enfoca principalmente este género, Lejeune demuestra que, incluso si este cotejo con la realidad fuera posible, no constituiría un criterio suficiente para definir la autobiografía en su particularidad. El contenido verdadero es propio de todos los textos referenciales, incluso los científicos; de ninguna manera es exclusivo de la autobiografía.

Resulta entonces imprescindible analizar, de cerca, qué tipo de verdad enfoca la autobiografía y cómo la expresa, porque, de hecho, el pacto referencial

\footnotetext{
${ }^{4}$ Ver Chihaia, M., "Bolaño y yo. Las dos caras de la autoficción en la obra de Roberto Bolaño" en Toro, V. y Schlickers, S., Luengo, A. (eds), 2010, pp. 141-153, Tornero, A. (2014), etc.

${ }^{5}$ Ver Chihaia, M., "Bolaño y Drácula. Cuatro modelos para hablar del autor" en Hennigfeld, U. (ed.), 2015, pp.155-170.
} 
es más propio de la biografía que de la autobiografía. Por tanto, la referencialidad no puede ser el criterio que contribuya a deslindar el género autobiográfico de este otro género vecino. Lejeune nos hace ver también que, si los planteamientos contenidistas caen en este error, los de corte formal no son menos equivocados porque, al considerar solamente el nivel textual, analizando unas técnicas y unos procedimientos descontextualizados, no son capaces de deslindar la autobiografía de otro género vecino, a saber: la novela de asunto autobiográfico (pp. 49-87). La propuesta de Lejeune es de índole totalmente distinta, pues supera con creces las definiciones que proponen una serie de requisitos formales o temáticos y parecen fórmulas algebraicas del tipo $\mathrm{A}$ (utor)= $\mathrm{N}($ arrador $)=\mathrm{P}($ ersonaje $) \mathrm{o}$, en el caso de la autoficción, la más sofisticada, propuesta por Genette (1993, p. 71):

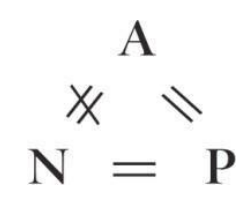

y, al mismo tiempo,

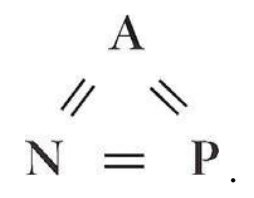

Para Lejeune (1994), lo definitorio del género es el -contratol que establece con el lector, al que le propone una determinada manera de leer como la apropiada y pertinente. De modo que, en su concepción y con sus mismas palabras, la autobiografía vendría a ser - un modo de lectura tanto como un tipo de escriturall (p. 87). El lector de la autobiografía debe aceptar que no la puede leer como si de una novela se tratara, sino que el texto que se dispone a leer reclama una lectura diferente. No se trata de que la autobiografía tuviera la pretensión absurda de imponerle dictatorialmente al lector su verdad, vista como definitiva y absoluta. Sino que el contrato consiste en hacer aceptar al lector que la lectura apropiada para este texto es la que, a diferencia del pacto novelesco, considera pertinentes las categorías verdadero/falso, así la contrastación con la realidad no se pueda realizar o no confirme lo afirmado por el texto autobiográfico.

Lo que el contrato autobiográfico requiere del lector es fe en la intención del texto de decir la verdad y no en la incomprobable verdad de los hechos. Requiere que el lector reconozca la importancia de la apuesta por decir la verdad, y que, por ejemplo, no la considere un aspecto irrelevante. Desde luego, el contrato de Lejeune es un fenómeno histórico: implica un contexto social, cultural, dentro del cual es válido. Por fuera de este, es nulo o sin sentido. Por tanto, una definición pertinente de la autobiografía requiere un enfoque que tenga en cuenta la relevancia del aspecto pragmático, y que permita entender el contexto en el que se cierra el pacto, para desentrañar su significado.

A continuación de este -malentendido originall viene otro, más grave aún, que confunde el pacto autoficcional con uno referencial, cuando ya con Lejeune queda claro que ni siquiera el pacto autobiográfico es un pacto referencial. De aquí se deduce que, con más razón aún, no lo es el pacto autoficcional, que apela declaradamente a las posibilidades expresivas de la ficción a la hora de verbalizar verdades del yo. Desde luego, tampoco las concibe como verdades referenciales. Su lectura literal constituye un grave error de recepción. ${ }^{6}$ Por ende, el malentendido aclarado hace décadas por Pozuelo Yvancos sigue proliferando como si nada hubiese pasado y, hoy en día, da pie a uno de los lugares comunes más reiterados y quizás más dañinos, si se considera su capacidad de desenfocar el todavía frágil concepto de autoficción, pues orienta la discusión teórica ha-

\footnotetext{
${ }^{6}$ En el caso de la obra de Fernando Vallejo, he estudiado este aspecto en "La Virgen de los sicarios frente a la «sicaresca». Un problema de recepción" (Diaconu, 2013, pp. 237-264)
} 
cia un rumbo totalmente errado. Este equívoco desemboca, por ejemplo, en la conexión errónea de la autoficción con la narrativa testimonial, independientemente de si los dos géneros son confundidos o contrapuestos tajantemente. ${ }^{7}$ Otro —clásicoll mal leído es, a mi modo de ver, Doubrovsky, al que también se le clasifica erróneamente, según lo explico más adelante.

Los estudios avanzan solo aparentemente, o mejor dicho se multiplican, porque no están orientados en la dirección correcta. No se puede hablar todavía de una teoría de la autoficción, cuyo desarrollo es superficial, sino de un compendio de lugares comunes y de vicios recurrentes de recepción. El aparente fenómeno de efervescencia no pasa de ser una fiebre editorial y congresil: en vez de construir ladrillo por ladrillo, empezando la casa desde abajo, una teoría del género, hoy en día, el discurso sobre la autoficción es de otra índole, no precisamente benigna, y crece en todas las direcciones. Parece ser una de estas célebres e interminables conferencias del famoso profesor Lucius J. Berry de Estados Unidos, inspirado personaje que inventa Jorge Volpi (2004) para ponerle en la boca todos los lugares comunes sobre la nueva narrativa latinoamericana. El profesor Berry, tan fantástico y a la vez tan real, el que ayer vaticinaba la muerte de la literatura latinoamericana, hoy nos habla de la autoficción.

Miremos entonces de cerca los lugares comunes en las propuestas teóricas actuales sobre el tema que nos ocupa:

\section{El mito fundacional}

En el principio, fueron las casillas vacías de Lejeune (1994). Magnificadas por una visión exagerada y unilateral, que las transforma en útero materno, las famosas casillas nos quitan hoy toda perspectiva: no permiten ver que la esencia de la propuesta de Lejeune no está en el esquema, sino en los comentarios que lo matizan. En las casillas se dejan encerrar y sistematizar los aspectos temáticos y formales, es decir el — momento técnicoll del pacto autobiográfico. Sin embargo, la novedad y la esencia de la definición de Lejeune están en otra parte: en el protagonismo que adquiere el aspecto pragmático.

Al definir la autobiografía, Lejeune no le destina una sola casilla, sino toda una zona en el mapa que dibuja el cuadro, una zona que, desde luego, se mueve con la historia. A continuación, Lejeune amplía todavía más esta zona, mostrando, a raíz de un caso concreto, cómo, en determinadas circunstancias, el espacio autobiográfico puede invadir también parte del campo de la novela, de manera que obras concebidas como ficción terminan siendo leídas según las leyes del pacto autobiográfico. Por consiguiente, la propuesta de Lejeune es todo lo contrario de una definición rígida y petrificada: es flexible, porque es histórica. El concepto mismo de - contratoll implica el reconocimiento de su dependencia del contexto cultural y social en el que se cierra y adquiere validez. Entonces, la definición de Lejeune no es nada esquemática, al contrario: es flexible y matizada, y por eso cuando se hace demasiado énfasis en el famoso cuadro, en realidad se está traicionando el verdadero espíritu de su propuesta.

¿Y el padre? Como padre de la autoficción, muchos críticos proponen a Doubrovsky, aunque, a mi modo de ver, confunden al padre con el padrino. Doubrovsky no es el inventor, sino un autor que reflexiona sobre el género y propone un término inspirado para designar una realidad ya existente. Como siempre ha pasado, el fenómeno literario es anterior a su teorización. Volveré sobre este asunto.

Otro tipo frecuente de error de recepción son las falsas diacro-

\footnotetext{
${ }^{7}$ Este tipo de enfoque es recurrente. Valga aquí como ejemplo el artículo que firma Gilberto D. Vásquez Rodríguez en la última antología publicada sobre la autoficción (Casas, 2014, pp. 79-105). Nótese que, siendo profesor de la misma Universidad de Murcia, Vásquez Rodríguez ignora totalmente los planteamientos de Pozuelo Yvancos.
} 
nías y - evoluciones del géneroll. Casi siempre se le ubica al - padrell en el capítulo - Autoficción y autobiografíall, dedicado a la prehistoria del género y a los próceres. Por ejemplo, en la introducción ${ }^{8}$ al libro $\mathrm{La} a u$ toficción. Reflexiones teóricas (Casas, 2012) se puede leer:

-en un primer momento, por lo tanto, la autoficción nace muy apegada a la autobiografía en tanto que expresión experimental de esta. Poco después, a mediados de los ochenta, empieza a vincularse también a la novela [...]\| (p. 17). En realidad, el texto de Doubrovsky, incluido en la misma antología, demuestra lo contrario. El autor se refiere a su -novela Fils| (p. 50), cita a Michel Leiris a propósito de sus escritos que define como -la negación de una novelall $(\mathrm{p}$. 48) y deja entender el contexto en el que surge su propuesta autoficcional: el deseo, la necesidad que siente de explorar otra manera de narrar, que permita —decir (sobre sí mismo y, de paso, sobre el otro) la verdad\| (p. 48). Desde luego, no se trata de una verdad referencial sino de una verdad interior, relativa, movediza, múltiple.

Igual que Doubrovsky, más de un narrador contemporáneo ha sentido un malestar frente a la novela como género poco apto para expresar esta clase de verdades, por su carga de con- venciones y su larga tradición idealista. De este malestar nace el impulso para innovar, para explorar otros caminos. En el fondo, lo que quiere escribir Doubrovsky no es una autobiografía, sino una novela diferente que le permita sortear estas limitaciones del género.

En la literatura latinoamericana, un ejemplo revelador en este sentido es el caso de Roberto Bolaño. Tanto su deseo de transgredir las pautas del género novelesco, como el infinito cansancio que le provocaban las autobiografías, son notorios. Sin embargo, según observa Matei Chihaia (2010), el rechazo tajante de lo autobiográfico y, sobre todo, de lo memorialístico, de una parte $y$, de otra, la distancia categórica que toma de la literatura de consumo, escrita desde el punto de vista de un -nosotros\| conformista, deja abierta una tercera posibilidad, que a menudo coincide con la salida por la que opta el discurso autoficcional: -el momento autobiográfico dentro de la ficción sirve para constituir un narrador individual, para evitar el peligro de perderse, de sumirse en el -nosotros\| pantanoso de las novelas escritas al gusto del gran públicoll (p. 142). No es otro el sentido del rechazo vehemente de Fernando Vallejo por la novela en tercera persona y con narrador omnisciente.
Después de haber dedicado varios años al estudio de la trayectoria de Fernando Vallejo, del camino por el que llega a la autoficción, a raíz de este caso concreto, he podido convencerme también de que el nuevo género autoficcional nace como una reacción frente al pacto novelesco y a las convenciones de la novela, y no como una variante de la autobiografía. Se origina así una nueva - serie literariall (en Vollek, 1992, p. 260), en términos de Tyniánov, una mutación de la novela, nuevo engendro que se desprende de su tradición (y no de la tradición autobiográfica), como consecuencia de complejas transformaciones histórico-culturales. $\mathrm{Su}$ aparición responde a la necesidad de preservar el carácter inacabado y el espíritu crítico y autocrítico, según Bajtín, propio de la novela, en una época en que las convenciones sofocan el género, convirtiéndolo en presa fácil de la industria cultural y del consumo masivo. Los resguardos más eficaces ante la manipulación ideológica y la banalización generalizada están sugeridos por el propio nombre de la autoficción y son altamente subversivos: la imaginación, que burla toda censura, y las insondables profundidades del yo -es decir, dos elementos esenciales, al mismo tiempo, para problematizar las relaciones

${ }^{8}$ La introducción se titula "El simulacro del yo: la autoficción en la narrativa actual", y forma parte, según se aclara en una nota al pie, del proyecto "Figuraciones del yo y representación autoficcional en narrativa, cine, teatro y novela gráfica en el marco de la teoría de los géneros" (Casas, 2012, pp. 9-42). 
complejas entre la escritura y la experiencia-.

Fernando Vallejo empieza su indagación artística en el cine, del que se desengaña pronto. Según narra en el tercer tomo de El río del tiempo, Los caminos a Roma (de 1988), al poco tiempo de presentarse en el famoso Centro Experimental de Cine de Roma, donde no lo reciben, pierde todo respeto por este arte que le parece más bien efímero y agotado, demasiado pobre en recursos expresivos, demasiado convencional, en breves palabras, - un embeleco del siglo xx\| (Ospina, 2003). Pronto, y por razones muy parecidas, se desencanta también del género biográfico, dentro del cual se sitúan sus comienzos literarios y al que había recurrido en un primer momento, deseoso de romper con el código literario enajenante en el que se había convertido el género de la novela. En palabras del propioautor:

Alguna vez [...] intenté hacer de la biografía un gran género de la literatura. Pensaba que se podía hacer de la biografía un gran género que desbancara la novela. Y no se puede, la biografía es un género menor. Una gran biografía es una gran biografía, nunca será un gran libro. La biografía está llena de abrir y cerrar comillas, de fechas, de nombres. En última instancia el escritor es como un portero que deja o no deja entrar gente, que abre y cierra comillas. Puede tener frases bien hechas, pero nunca será un gran género. Entonces, el gran género de la literatura tenía que ser la novela. (Diaconu, 2013, pp. 351-352) ${ }^{9}$

Al enfocar el fenómeno desde una altura que permita abarcar todo el campo literario latinoamericano, se puede observar que muchos de los nuevos narradores del así llamado posboom sienten la misma necesidad de desprenderse de la gloriosa (pero también anquilosada) tradición novelesca inmediatamente anterior, la gran novela de los sesenta, para reconectar el discurso literario con la realidad y con la verdad. Se diría que las nuevas voces de la narrativa latinoamericana buscan, cada una, su -salida del archivol (González Echevarría, 2011, p. 259); es decir, la manera de desprenderse y de dejar atrás el discurso americanista entendido como discurso hegemónico. Pero esto no significa que se aparten de la novela para dedicarse a cultivar otros géneros literarios, sino para asimilar realmente esta tradición, en la cual reconocen el gran género literario, pese a todos sus vicios. Muchas de las nuevas voces de la narrativa latinoamericana apuestan por enlazar con esta gran tradición de manera creadora, enriquecedora, crítica, a menudo conflictiva también, reformando y reinventando el género, y no siguiendo sus pautas al pie de la letra, como meros epígonos.

La - salidall que finalmente encontrará Fernando Vallejo es la autoficción, sin duda uno de los nuevos caminos más prometedores de la literatura latinoamericana del posboom. Pero antes de dar con el género que le permitiera expresar las verdades de su yo (entendido no en su dimensión psicológica, sino fenoménica, como manera de relacionarse el sujeto con la realidad), se tendrá que desencantar del pacto referencial, en el que, en un primer momento, ve la única alternativa al género -manidoll de la novela. No tarda en advertir sus limitaciones severas a la hora de tratar la realidad: por eso, en su concepción, tanto el cine, como la biografía, e incluso la autobiografía, son géneros superficiales, anecdóticos. Conviene entonces echar mano, nuevamente, de las palabras del propio escritor para invalidar de una vez por todas las hipótesis según las cuales la autoficción sería una variante (posmoderna) de la autobiografía:

El gran género de la literatura es la novela. Lo que

${ }^{9}$ La entrevista se realizó durante el Carnaval Internacional de las Artes de Barranquilla (18 de enero de 2008). 
pasa es que este camino de la novela en tercera persona y con un narrador omnisciente, que sabe todo lo que les pasa a los personajes, que repite sus diálogos, es un género que ya está muerto. Además de que este planteamiento es falso, va en contra de la realidad porque la mente es muy caótica y las conversaciones son irrepetibles y a las personas no las conocemos, casi ni la propia. Es un género manido, un camino trillado, muy recorrido y que no va para ningún lado. Entonces empezó a aparecer otro género al que yo llegué no por reflexión sino por instinto y por rechazo al otro, al que conocía muy bien porque era la literatura que leía de niño, y que me gustaba. Apareció una nueva novela basada en la vida del autor, pero esta novela, de las llamadas de autoficción, distaba mucho de ser una autobiografía o un libro de memorias. (Diaconu, 2013, p. 350).

La reflexión espontánea de Fernando Vallejo, en la misma entrevista, muestra la clara conciencia del autor de que el nuevo género autoficcional representa una toma de posición (Bourdieu, 1997) ante la novela existente, se deriva de ella, surge del diálogo con ella, así sea negándola, aparentemente.
En realidad, cuestionándola, invitándola a renovarse, no a desaparecer, reivindicando las funciones sociohistóricas y culturales de la ficción.

Y por fin, otro lugar común que es casi un mito: la creencia -insensata e injustificada- de que, a diferencia de otros géneros literarios, la autoficción tiene una fecha exacta de nacimiento: 1977. Muy buenos contraargumentos se encuentran en el libro de Manuel Alberca (2007), El pacto ambiguo. De la novela autobiográfica a la autoficción (pp. 140-163), que desmonta dos mitos de un solo tiro: este y su contrario, igualmente falso, según el cual el origen de la autoficción se perdería en la oscuridad de los tiempos. Desde luego, la existencia de relatos con las características formales de la autoficción o de textos que ficcionalizan el yo autorial se puede comprobar en épocas muy remotas, pero una vez más este tipo de enfoques demuestra sus insuficiencias para dar cuenta del género. Alberca advierte que, si aparentemente estos textos son semejantes, en el fondo son muy diferentes: remiten a unos conceptos de sujeto y de individualidad muy distintos de los que están detrás de las autoficciones actuales. Además, el amplio desarrollo que conoce el género en pocos años permite deducir que estamos ante un fenómeno directamente relacionado con la época contemporánea, con la crisis de la modernidad y la entrada en la así llamada posmodernidad.

A pesar de ser contrarias, ambas tesis desmontadas por Alberca proceden de enfoques contenidistas y de corte formal, que en un primer momento de euforia lo ven todo nuevo, para luego tener que reconocer que todo lo había hace tiempo ya. Por eso, es frecuente la afirmación de que fue Doubrovsky quien llenó las casillas vacías de Lejeune, en 1977. Pero no menos frecuentemente se lee que, en realidad, hace rato que las casillas de Lejeune no están vacías. El problema de fondo de este tipo de planteamientos es el abandono de la visión histórica, clave para el enfoque de todo género literario.

Ahora bien, recurriré nuevamente a las palabras de Fernando Vallejo para demostrar con su testimonio que, si bien la autoficción es un fenómeno contemporáneo, 1977 no es la fecha de nacimiento del género, sino la fecha de su bautismo y del comienzo de la reflexión teórica sobre la autoficción:

- [...] yo nunca he leído muchos textos de análisis literario sobre esto que llaman el pacto autobiográfico, o la autoescritura. Yo no los leo porque ¿para qué? Yo lo estaba haciendo antes de que ellos reflexionaran sobre estoll (Diaconu, 2013, p. 351).

\section{El mal francés}


Para quienes consideran, como el profesor Berry, que el progenitor de la autoficción es Doubrovsky, no cabe duda tampoco de que se trata de un género nacido en Francia y rápidamente -exportadoll a todo el mundo gracias a la globalización, es decir, de la -internacionalizaciónll del fenómeno.

La idea del nacimiento del género en Francia no es nueva (ni tampoco muy resistente), pero convence a la mayoría de los críticos. Quizás no solo convence, sino que también conviene: situar el nacimiento del género en un país lejano, como hacían los libros de caballerías con sus tramas increíbles, es una manera simplista, fácil, de tratar un asunto tan complejo como el surgimiento de un género. Y de paso, una maniobra hábil que consiste en pasarles la pelota a los teóricos franceses. Varios críticos nos informan, de manera escueta, que esta novedad posmoderna nos llega de Francia, lo mismo que antes se había afirmado sobre el ensayo, género moderno. Ciertos vicios de la crítica parecen ser hereditarios. Un trabajo de referencia sobre el ensayo hispanoamericano ${ }^{10}$ propone, hasta cierto punto, un planteamiento prometedor en su intento de definir el espíritu del ensayo como género, su manera propia y única de enfocar la realidad; es decir, en términos de Bajtín, su -forma arquitectónicall $(1989$, p. 60$)$, y no solamente su -forma composicionall. Pero la propuesta queda truncada cuando, al abordar la evolución del género, se pretende explicar su aparición con la obra de un ilustre antepasado: Montaigne.

Muchos años después, el error se repite al enfocar esta vez el género de la autoficción: el progenitor es ahora nuestro contemporáneo, Doubrovsky, pero Francia sigue siendo la cuna. Según la introducción a la Breve historia del ensayo hispanoamericano (Oviedo, 1991), Montaigne era el -iniciadorl ( $p$. 17) del ensayo y Francia su país de -nacimientol, aunque -tuvo un crecimiento e importancia mayores en Inglaterra [...]. De Inglaterra, el género se diseminó rápidamente en otras lenguas [...]\| (p. 19). El final de la introducción es abrupto y deja entender que el género fue importado a América Latina. En los mismos términos, se nos cuenta hoy la evolución del género de la autoficción, en la introducción de una de las antologías más recientes: La autoficción. Reflexiones teóricas (Casas, 2012). Nada ha cambiado en el fondo. A pesar de que, leída en América Latina, esta explicación, rápida y convencional, revela todavía mejor sus insuficiencias y el absurdo de la situa- ción que supone, pues resulta completamente inverosímil que tantos escritores latinoamericanos estén cultivando un género inventado por unos lejanos, o incluso, para ellos, desconocidos franceses, llámense Montaigne o Doubrovsky.

La idea del nacimiento de sendos géneros en Francia tiene detrás una concepción del género literario realmente anacrónica, según la cual este es el invento de un solo individuo genial. Nada se nos dice sobre las necesidades expresivas de la época, a las que obedece su aparición, sobre las posibilidades expresivas nuevas, inexistentes en los demás géneros, que el nuevo género aporta. ¿Qué necesidad histórica, cultural y existencial conlleva la aparición de la autoficción? ¿Cómo participa este individuo genial de la cultura de su época? Las verdaderas preguntas, difíciles de contestar, quedan soslayadas por este tipo de planteamiento. La respuesta solo puede resultar de un perspicaz estudio del contexto cultural y del campo literario en el que se enfrentan las diferentes propuestas antagónicas.

\section{La muerte de la autobio- grafía}

Según el profesor Berry (y su prolija descendencia), la autobiografía ha muerto. Es un lu-

\footnotetext{
${ }^{10}$ Se trata del estudio de José Miguel Oviedo (1991) “Introducción. Naturaleza y orígenes de un género" en Breve historia del ensayo hispanoamericano.
} 
gar común afirmar que, en la posmodernidad, el género moderno de la autobiografía se ve reemplazado por la autoficción. Definitivamente no se puede poner un signo igual entre autoficción y posmodernidad, a no ser que lo hagamos por destacar la suerte que corrieron ambos conceptos: muy prometedores en un comienzo, acabaron desdibujándose hasta quedar vacíos de todo contenido preciso.

La idea tuvo una amplia acogida a pesar de ser totalmente falsa, ya que nace de una visión maniquea que opone rígidamente la autoficción a la autobiografía, asociándolas a los binomios, no menos esquemáticos, posmodernidad vs. modernidad, presente vs. pasado. Se le superpone la interpretación errónea de unas muy citadas afirmaciones de Doubrovsky. ${ }^{11} \mathrm{Si}$ bien Doubrovsky concibe la autoficción como un género que, a diferencia de la autobiografía, responde a un nuevo concepto de verdad y a unas necesidades culturales distintas, siendo apto para expresar verdades íntimas, múltiples, contradictorias, movedizas como el yo del sujeto contemporáneo, no se debe olvidar que su término de referencia no es la autobiografía sino un tipo determinado de autobiografía: la autobiografía clásica, sofocada por una retórica anticuada y convencional. Deducir de esto que toda autobiografía concibe la verdad del sujeto como única, indiscutible y definitivaes un grave error. Varios críticos sepultan así precipitadamente un género versátil, que goza todavía de buena salud.

Declarar la muerte de la autobiografía, argumentando que la autoficción desplaza a la autobiografía, igual que la posmodernidad desplaza a la modernidad, es definitivamente una manera demasiado esquemática y facilista de encarar problemas muy complejos. Autobiografías como la de Sartre (Las palabras, 1966) y, más recientemente, la de Juan Goytisolo, en dos tomos, Coto vedado (1985) y En los reinos de taifa (1986), prueban que el género tiene más recursos y vigencia de lo que algunos teóricos de la autoficción dejan entender. Fácilmente, se puede demostrar que estos textos autobiográficos, convertidos ya en nuevos clásicos a pesar de su corta edad, no pecan por ninguno de los vicios que le censura Doubrovsky a la autobiografía tradicional, no son en absoluto retóricos, ni convencionales, sino todo lo contrario; $\mathrm{y}$, sin embargo, no por esto son autoficciones.

\section{El relato médico}

Con la vasta experiencia que tiene, el profesor Berry sabe que el momento técnico, en jerga incomprensible, no puede faltar en la exposición. Infligir al lector una buena lección de humildad, lograr que se sienta lego, que se esfuerce, que se aburra, que se vuelva a empeñar en redondear algún sentido, para finalmente tener que aceptar en su foro interior que no comprendió absolutamente nada. El maestro Genette y sus discípulos (Colonna, Darrieussecq) nos hablan de análisis paratextual, peritextual, epitextual, aderezado con un toque metatextual y, para concluir, con la infaltable proyección intertextual. Las últimas antologías sobre la autoficción abundan en planteamientos inspirados en Genette y la narratología (Toro, Schlickers, Luengo, Gil Guerrero, etc., en Toro, Schlickers, Luengo, 2010; Champeau, citado en Casas, 2012; Roger, en Casas, 2014). Sin embargo, esta vía lleva invariablemente a un callejón sin salida: si bien las observaciones sobre diferentes técnicas o procedimientos literarios puedan ser, en sí, pertinentes, la mirada miope y descontextualizadora los aísla y absolutiza hasta convertirlos en piedra de toque para decidir

\footnotetext{
${ }^{11}$ Nótese que la cita no procede de un texto de reflexión teórica, sino que acompaña, como paratexto aparecido en la contraportada, la novela Fils (1977). La reproduzco aquí en la traducción de Manuel Alberca: “¿Autobiografía? No. Es un privilegio reservado a las personas importantes de este mundo, en el ocaso de su vida, y con estilo grandilocuente. Ficción, de acontecimientos y hechos estrictamente reales; si se quiere, autoficción, haber confiado el lenguaje de una aventura a la aventura del lenguaje" (Alberca, 2007, p. 146).
} 
si una obra es o no una autoficción.

Por tanto, se pierde de vista que cada uno de estos procedimientos, lejos de encarnar el espíritu del género, es apenas una de sus manifestaciones concretas, una posibilidad, entre otras, que tiene el texto para cerrar el pacto de lectura propio de su género. En la medida que ningún procedimiento literario es exclusivo de ningún género, el análisis de aquellos resulta, desde luego, totalmente insuficiente para abordar la autoficción. La mirada descriptiva reduce el análisis al inventario de los -juegos autoficcionalesll, acompañado a menudo por alguna propues- ta de tipología, para finalmente llegar a conclusiones modestas, si no directamente irrelevantes. El comentario parecería seguir una orden médica, una fórmula, una receta, puesto que cualquier sobresalto o sorpresa le son ahorrados al lector. Pero además, esta mirada conlleva también una visión estática de lo que es el género, que impide tomar el pulso de su auténtica vida para concebirlo como un paradigma en marcha, como ya sugería Tyniánov.

No obstante, se ven a menudo propuestas que consideran la presencia de la metalepsis como un síntoma suficiente para poner el diagnóstico irrevocable de -autoficciónll, o para incluir un artículo en una antología sobre el género (Schlickers, en Vera,
Schlickers \& Luengo, 2010, pp. 51-71; Champeau, en Casas, 2012, pp. 261-281). Todavía más grave me parece que eleven este procedimiento hasta conferirle estatuto de criterio de toda una antología y lo entronicen en el propio título, como ocurre en el libro que editan Toro, Schlickers y Luengo (2010) con el término de -auto(r)ficciónll, al que justifican así: - ...nos parece arbitrario clasificar tan sólo aquellos textos con homonimia completa como autoficcionales. [...] Para no simplificar las cosas demasiado, añadimos una «r» en la palabra compuesta, para incluir aquellos relatos ficcionales en los que hay una =intromisión' del autor in corpore o in verbis en el mundo narradoll (pp. 20-21). ¡Como si la intrusión del autor -tan frecuente en el realismo decimonónicofuera lo mismo que la identidad nominal entre autor, narrador y personaje!

Abordar la autoficción con presupuestos de la teoría de la recepción, evitaría confusiones de este tipo, porque permitiría tomar conciencia de la manera tan diferente, incluso opuesta, en que se prefigura el lector en las narraciones autoficcionales, de una parte $y$, de otra, en aquellas narraciones donde se dan intrusiones del autor y que a menudo son en tercera persona y con narrador omnisciente. En otros planteamientos, es recurrente la obsesión fetichista por los paratextos (Arroyo Redon- do, en Casas, 2014, pp. 65-77) o por lo metaliterario y la intertextualidad (Roger, en Casas, 2014, pp. 227-245), con total olvido de que estos fenómenos no son exclusivos de la autoficción, si bien su análisis resulta casi siempre revelador en toda obra literaria.

Cuando lo metanarrativo, metadiscursivo, metaficcional, metaliterario, etc., se convierten en las únicas metas del crítico, igual que ocurre, en otros casos, con lo intertextual, paratextual, peritextual, epitextual, etc., la autoficción se ve convertida en juguete y su lectura en una actividad lúdica, aparentemente entretenida, pero realmente poco creadora. El endotexto parece que todavía no existe, pero no tardarán en inventarlo: nuestro optimismo se basa en la existencia del peritexto. La autoficción se ve tratada por una serie de críticos como si fuera paciente en silla de odontólogo u otras veces paciente psiquiátrico. Todo parece anunciar nuevos capítulos en la teoría de la autoficción de tipo: - Autoficción y odontologíall o - Autoficción y psicoanálisisll. Pura medicina, o si prefieren, puras -fantasías textuales\| para recordar el buen humor de Fernando Iwasaki, que tanta falta les haría a este tipo de estudios desangelados.

Pero el profesor Berry, como cualquier especialista de hoy bien entrenado para hablar en los congresos, sabe que la im- 
portancia de este momento es vital también de cara a la catarsis final, ya que en el último punto vienen las infaltables listas de autores, donde el público siente con alivio que se le devuelve el sentido y toma apuntes precipitadamente. Por fin se entera de quiénes son. Y así, de la abstracción más abstrusa del discurso médico, aterrizamos de repente en medio del concreto más anecdótico: unos nombres que designan con precisión estricta (y estrecha) a los autores que - cometieronll autoficciones.

\section{Las listas de autores}

No suelen faltar, en las propuestas de hoy, las largas enumeraciones de nombres de autores. Pero el criterio de selección, a menudo demasiado amplio $\mathrm{y}$ laxo, convierte estas listas en el momento más arbitrario de muchos estudios: verdaderas listas de reclutamiento para enrolar a autores con trayectorias de lo más dispares bajo una dudosa bandera. Razón por la cual, las famosas e infaltables listas tampoco pasan de ser un saludo a la bandera. Consideremos un ejemplo extraído de una propuesta muy reciente: el estudio introductor titulado - La autoficción en los estudios hispánicos: perspectivas actuales\| de la recopilación El yo fabulado. Nuevas aproximaciones críticas a la autoficción (Casas, 2014):
...Carmen Martín Gaite, Jorge Semprún, Francisco Umbral, Enrique Vila-Matas, Javier Marías, Antonio Muñoz Molina, Javier Cercas, Antonio Orejudo, Gonzalo Hidalgo Bayal, Luisgé Martín, Marta Sanz, Manuel Vilas, en España; César Aira, Sylvia Molloy, Ricardo Piglia, Félix Bruzzone, Patricio Pron, Alan Pauls, Daniel Guebel, Laura Alcoba, Washington Cucurto, en Argentina; Mario Levrero en Uruguay; Sergio Pitol, Mario Bellatin, Margo Glantz, Angelina Muñiz-Huberman, Alejandro Rossi, Julián Herbert, Guillermo Fadanelli, en México; Fernando Vallejo, Daniel Jaramillo, ${ }^{12}$ en Colombia; Patricia de Souza en Perú; Pedro Juan Gutiérrez en Cuba; Rodrigo Rey Rosa en Guatemala; Luis Barrera Linares en Venezuela, entre otros muchos, han practicado la autoficción en sus distintas modalidades (pp. 10-11).

Semejantes enumeraciones, muy frecuentes en los estudios de hoy, podrían ser producto de un desdén de la teoría, muy propio de la época posmoderna: el afán de dejar de lado las abstracciones y las generalidades para privilegiar los textos y los casos concretos, propósitos muy invocados últimamente. Sin embargo, en este tipo de planteamientos hay un gran olvido: no se tiene en cuenta que no hay manera de contestar las preguntas, tan recurrentes e insistentes, a veces, ¿quiénes son los autores de autoficciones?, ¿fulanito de tal escribe autoficción, sí o no?, sin haber reflexionado, seria y profundamente, sobre la concepción del género, de la cual la respuesta depende totalmente. Vírgenes de teoría, las listas de autores son un saco roto, en el que cabe todo: cualquier híbrido entre novela y autobiografía, cualquier -figuraciónll de un yo. En esta óptica, resulta hasta difícil distinguir la autoficción de la literatura.

La idea con la que acaba el breve recorrido teórico sobre el género que nos propone el libro La autoficción. Reflexiones teóricas (Casas, 2012), en su introducción, es sintomática para este tipo de planteamiento: -el propio término autoficción alude, pues, a un hibridismo que admite todas las gradaciones $y$, por ello, resulta extremadamente lábil como concepto\| (p. 11) Pero si la autoficción ocupa un espacio tan -ampliol y bajo este término —encuentran acomodo textos de muy diversa índolell (p. 11), entonces hablar de un pacto autoficcional carece por completo de sentido, es más, ¿qué sentido tiene seguir ha-

\footnotetext{
${ }^{12}$ Supongo que se trata de una errata y el texto se refiere al escritor colombiano Darío Jaramillo Agudelo.
} 
blando todavía de la autoficción como género?, ¿cómo se puede defender paralelamente la idea de que todos los textos analizados pertenecen a una misma - serie literariall en el sentido de Tyniánov y, por tanto, los textos críticos que los enfocan pueden ser reunidos en una antología sobre la autoficción?

En realidad, en estos tipos de planteamientos la idea misma de género se esfuma, siendo reemplazada por la palabra -conceptoll, que funciona más como palabra que como concepto. Resultados muy parecidos a los enfoques formales o temáticos de la autoficción producen aquellos planteamientos que pretenden ofrecer una mirada muy abarcadora, la cual, sin embargo, resulta borrosa, ya que se ignoran las posibilidades expresivas de cada género o de cada arte en particular, actualizadas en campos específicos de producción de sentido. Algunas de estas propuestas proceden del campo de los estudios culturales y su visión se debe a una impaciencia por rebasar toda frontera y al culto, a mi modo de ver, exagerado, que se le rinde a la interdisciplinariedad. Como si los estudios literarios no fueran, de todos modos, interdisciplinarios, por su misma naturaleza. $\mathrm{O}$ bien, se trata de estudios que identifican apresuradamente el sujeto narrativo con el sujeto dramático y hasta con el yo lírico, trasladando de manera imprudente plantea- mientos teóricos sobre la narrativa al campo de la poesía (Laura Scarano, Ana Luengo), de las artes visuales (Sabine Schlickers, Javier Ignacio Alarcón), escénicas (Vera Toro, José-Luis García Barrientos), etc., o adoptando sin las debidas precauciones categorías creadas en estos otros campos, para estudiar la narrativa. Así, por ejemplo, Fernando Cabo Aseguinolaza (2014) aplica a la autoficción el concepto de -teatralidadll, nacido en el campo de la historia del arte, con el fin de incorporar a la reflexión la perspectiva de —quien contempla- o leell (p. 31) y el propósito implícito de superar las visiones -restrictivas accediendo así a una -amplial. Pero ¿qué necesidad real hay de acudir a un concepto creado para estudiar fenómenos de otros campos, cuando la teoría de la recepción trata de manera específica y matizada el asunto del lector prefigurado por el texto? ¿No será que se trata de un afán muy contemporáneo de promover la interdisciplinariedad contra viento y marea, venga o no al caso?

Peor aún es la falsa creencia de que la única alternativa a este tipo de enfoques demasiado amplios y, por tanto, desenfocados e imprecisos, sería la vuelta a una definición - estrechall, —estrictall o — cerradall, aun planteamiento contenidista, que concibe la verdad como referencial. No: una definición rigurosa, según criterios claros, no tendría por qué ser necesariamente rígida; tampoco es huyéndole a la precisión como se supera la estrechez de miras. En la visión de Fernando Cabo Aseguinolaza, el concepto de autoficción se amplía hasta esfumarse: biografía, ensayo, crítica literaria, todo cabe dentro de lo que el crítico llama - los ejercicios autoficcionales, o como se quiera denominarlosll (p. 40). Su visión se corrobora en un estilo insinuante, alusivo, hasta cabalístico, abundante en palabras como -algoll y -cosall, para no tener que nombrar lo innombrable: la autoficción, que permanece envuelta en un velo de misterio. Al final, el crítico llega a referirse al -estallido autoficcional de la novela contemporáneall (p. 41): con esta explosión postrera, el concepto queda definitivamente pulverizado.

La indefinición del concepto acarrea otro problema recurrente en muchos estudios sobre la autoficción: la indefinición de la propuesta, ya que se renuncia de antemano a la visión coherente y a la toma de posición, con el pretexto de -iluminarl ciertos aspectos, ofrecer unas -clavesl. El autor apunta unas ideas que, en sí, hasta podrían ser valiosas, pero que se le entregan al lector sueltas, como un rompecabezas, como si fuera este quien debiera articular el sentido y tomar una posición, y no el autor. El estudio de Fernando Cabo Aseguinolaza (en Casas, 2014), -Tea- 
tralidad, itinerancia y lectura: sobre la tradición teórica de la autoficción\| (pp. 25-43), deja al lector esperando en el lugar equivocado $\mathrm{y}$ tan despistado como Lönnrot, el detective borgesiano de - La muerte y la brújulall ante los mensajes esotéricos del criminal Red Scharlach. Teatralidad: - La primera letra del Nombre ha sido articuladall. Itinerancia: - La segunda letra del Nombre ha sido articuladall. Lectura: - La última de las letras del Nombre ha sido articuladall. La nueva deidad Autoficción sigue siendo el gran misterio, el Nombre Secreto, el impronunciable Nombre de Dios...

En conclusión, las llamadas definiciones -ampliall y -estrechall de la autoficción no son dos caminos posibles, sino dos definiciones mal enfocadas, dos planteamientos equivocados, que conducen a conclusiones falsas. Ninguna de las dos definiciones es preferible a la otra: seguimos sin alternativa viable. En la introducción a la antología de 2014, Casas retoma esta idea de las dos clases de definiciones, defendiendo también la definición -amplial e intentando una imposible defensa de la -operatividad del términoll de autoficción, pese a su -labilidad conceptuall (p. 9). Para argumentar, invoca la propuesta de Manuel Alberca; sin embargo, a mi modo de ver, la presenta en su versión más pobre, insistiendo precisamente en sus puntos débiles, en vez de destacar sus aportes. A pesar de las vacilaciones de su planteamiento ${ }^{13}$ y de las categorías muy discutibles que propone (一autoficciones biográficasll, -autoficciones fantásticasll, -autobioficciones\|, etc.), en su intento de esbozar una tipología de la autoficción, Manuel Alberca reconoce la importancia del pacto específico para la definición del género, y prueba de ello es el mismo título de su libro: El pacto ambiguo. De la novela autobiográfica a la autoficción. Si bien hay pasajes confusos, donde se incurre en contradicciones, para Alberca, el pacto autoficcional es un nuevo pacto de lectura y no una hibridación del pacto ficcional novelesco y el autobiográfico, en cualquier grado. ${ }^{14}$

Es más, en últimas, el pacto autoficcional ni siquiera se define por la mezcla que respeta rigurosamente las proporciones, sino por la tensión que se genera entre los dos pactos antitéticos y se mantiene a una intensidad máxima a lo largo de toda la obra, sin resolverse en ninguno de los dos sentidos contrarios. De esta tensión constante, que es clave, debe emerger un sentido central en la obra, que no puede ser captado si no se indaga el significado cultural del género. Pese a que la palabra

- ambiguoll confunde y entra en conflicto con la misma idea de pacto $^{15}$, a mi parecer, las mejores páginas del estudio de Manuel Alberca se escriben teniendo plena conciencia de que la autoficción propone un nuevo pacto de lectura, bien definido, pero ambivalente. Desde mi punto de vista, es fundamental no confundir este pacto con uno ambiguo, en el sentido de indeterminado, que abarca obras en las que se mezclan, de cualquier manera y en cualquier proporción, el pacto novelesco y el autobiográfico.

La causa principal del desenfoque provocado por todos estos lugares comunes, que he analizado aquí, es el olvido de un aspecto esencial: el significado cultural de un género, que solo puede ser alumbrado entendiendo a fondo el contexto en el que surge. En una de las últimas antologías sobre el género, $L a$ autoficción. Reflexiones teóricas (Casas, 2012), se opta por el camino contrario al que creo que deberían seguir en la actualidad los estudios teóricos sobre la autoficción. Al final de la in-

\footnotetext{
${ }^{13}$ En su estudio aparecen, a menudo, los términos "novela autoficticia" y "autoficción" usados indistintamente, lo cual implica no reconocer la diferencia entre ambos pactos o considerar que no se trata de un asunto esencial.

${ }^{14} \mathrm{Cfr}$. "El relato autoficticio guarda una equidistancia simétrica con respecto a la novela y la autobiografía [...]" (Alberca, 2007, p. 130)

${ }^{15}$ Ver mis comentarios al respecto en Diaconu (2013, p. 48, nota 20), donde justifico mi preferencia por el término "ambivalente" en vez de "ambiguo".
} 
troducción, se concluye con la siguiente idea:

La antología se cierra con una bibliografía teórica sobre la autoficción y otras nociones afines o colindantes. Por esta razón, se han evitado las referencias a trabajos críticos que, aun siendo de gran interés, se limitan exclusivamente al estudio de obras, autores o periodos literarios (p. 42).

El grave error de la descontextualización de la obra produ- ce tanto el -discurso médicol como las - listas de autores\|, y condena el estudio crítico a permanecer en un callejón sin salida porque no le permite superar el nivel descriptivo, para emprender la búsqueda del significado. Al contrario, nos adentra en una selva tupida de observaciones sobre toda clase de malabarismos formales y de juegos con la visibilidad del autor, como si estos tuvieran algún valor intrínseco y fuera meritorio confundir por confundir, cultivar la ambigüedad por el amor al arte. En última instancia, todo esto ocurre porque el enfoque no permite indagar la escritura como un conjunto complejo de recursos formales necesarios para la construcción del sentido, sino que los valora como exhibiciones gratuitas, alabando excesivamente su alto grado de complejidad.

La consecuencia directa es que la lectura de estos estudios se convierte en una verdadera tortura. Más que nunca, haría falta reírse sabiamente de la autoficción, tema actual, apasionante y atractivo, del que se ha apoderado un discurso teórico de una seriedad estéril, abstracta y conformista, volviendo los textos indeseables, verdaderos quebraderos de cabeza. Recuperar la risa en el sentido de Bajtín y el placer del texto del que trata Roland Barthes.

\section{Referencias}

Alberca, M. (2007). El pacto ambiguo. De la novela autobiográfica a la autoficción. Madrid: Biblioteca Nueva.

Bourdieu, P.(1997). Las reglas del arte. Génesis y estructura del campo literario. Barcelona: Anagrama.

Bajtín, M. (1989). Teoría y estética de la novela. Madrid: Taurus.

Cabo, A. F. (2014). Teatralidad, itinerancia y lectura: sobre la tradición teórica de la autoficción. En A. Casas (ed.), El yo fabulado. Nuevas aproximaciones críticas a la autoficción. (pp. 25-43) Madrid/Frankfurt: Iberoamericana/Vervuert.

Casas, A. (2012). La autoficción. Reflexiones teóricas. Madrid: Arco Libros.

Casas, A. (2014). El yo fabulado. Nuevas aproximaciones críticas a la autoficción. Madrid/Frankfurt: Iberoamericana/Vervuert. 
Chihaia, M. (2010). Bolaño y yo. Las dos caras de la autoficción en la obra de Roberto Bolaño. En V. Toro, S. Schlickers \& A. Luengo (eds.), La obsesión del yo. La auto(r)ficción en la literatura española y latinoamericana. (pp. 141-153). Madrid/Frankfurt: Iberoamericana/Vervuert.

De Man P. (1991). La autobiografía como desfiguración. Suplementos Anthropos, (29), 113-118.

Diaconu, D. (2013). Fernando Vallejo y la autoficción. Coordenadas de un nuevo género narrativo. Bogotá: Universidad Nacional de Colombia.

Genette, G. (1993). Ficción y dicción. Barcelona: Lumen.

González E. R. (2011). Mito y archivo. Una teoría de la narrativa latinoamericana. México: Fondo de Cultura Económica.

Lecarme, J. (1994). L'autofiction; un mauvais genre? Ritm, 6, 227.

Lejeune, P. (1994). El pacto autobiográfico y otros estudios. Madrid: Megazul-Endymion.

Ospina, L. (2003). La desazón suprema: retrato incesante de Fernando Vallejo [película documental]. Colombia: Luis Ospina.

Oviedo, J. M. (1991). Breve historia del ensayo hispanoamericano. Madrid: Alianza.

Pozuelo Yvancos, J. M. (1993). Poética de la ficción. Madrid: Síntesis.

Pozuelo Yvancos, J. M. (2012). —Figuración del yoll frente a autoficción. En A. Casas (comp.), La autoficción. Reflexiones teóricas. Madrid: Arco Libros.

Scarano, L. (2007). Palabras en el cuerpo: Literatura y experiencia. Buenos Aires: Biblos.

Toro, V., Schlickers, S., \& Luengo, A. (eds.) (2010). La obsesión del yo. La auto(r)ficción en la literatura española y latinoamericana. Madrid/Frankfurt: Iberoamericana/Vervuert.

Tornero, A. (2015). Reflexiones sobre ficción, autoficción e identidad en Los detectives salvajes de Roberto Bolaño. Kaleidoscopio, (22), 45-56.

Tyniánov, I. (1992). Sobre la evolución literaria. En Volek, E. (ed.) Antología del formalismo ruso y el grupo de Bajtin. Polémica, historia y teoría literaria. Madrid: Fundamentos.

Volpi, J. (2004). El fin de la narrativa latinoamericana. En R. Bolaño, J. Franco, R. Fresán, S. Gamboa, G. Garcés, F. Iwasaki,... J. Volpi, Palabra de América (pp. 206-223). Barcelona: Seix Barral. 